\title{
An assessment of measured and computed depth of closure around Japan
}

\author{
Keiko Udo ${ }^{1 *}$, Roshanka Ranasinghe ${ }^{2,3,4}$ \& Yuriko Takeda ${ }^{1}$
}

The development of effective coastal adaptation strategies and protection schemes is a major challenge for coastal zone managers and engineers, not only because the coastal zone is the most populated and developed land zone in the world, but also due to projected climate change impacts. A priori knowledge of the so called depth of closure $(\mathrm{DoC})$ is, more often than not, a pre-requisite to understand and model coastal morphological response to wave forcing, which in turn enables the design of appropriate coastal adaption/protection measures. In the absence of long term measurements of coastal profile data, the DoC is often computed using Hallermeier's formulations or derivatives thereof, for applications around the world. However, there are two major unresolved issues associated with computing the DoC in this way: the accuracy of the wave data required for reliable DoC computations, and the generic applicability of the coefficients used in DoC equations. This study exploits the availability of DoCs derived from multiple measurements of coastal profiles and wave data along the Japanese coast together with wave reanalysis products to evaluate the validity of DoC calculation approaches. Results show that the accuracy of computed DoC values determined using wave reanalysis data is limited, particularly when the spatial resolution of the wave reanalysis data is lower. Furthermore, coefficients of DoC equations proposed in previous and present studies appear to be location specific and points toward the need for a concerted worldwide meta-analysis that compares observed and derived $\mathrm{DoC}$ in order to derive a globally applicable formulation for DoC computations.

The coastal zone is the most heavily populated land zone in the world ${ }^{1-3}$ with about $10 \%$ of the global population living within the low elevation coastal zones of the world ${ }^{4}$. As a direct result, there is vast amount of developments and infrastructure located within the coastal zone. While these coastal communities, developments and infrastructure are already threatened with coastal hazards like severe storms, king tides, and storm surges, climate change driven variations in mean seal level (i.e. sea level rise), waves and surges are expected to result in more frequent and more severe coastal flooding and erosion ${ }^{5,6}$. Therefore, the development of appropriate coastal zone management and protection strategies will be even more important in the future than it already is at present. However, the lack of phenomenological understanding and accurate prediction methods of long-term (i.e. decades or longer) coastal morphological response to forcing is a major challenge for sustainable coastal zone management.

The development of coastal adaptation strategies (e.g. establishment of setback lines) or the design of coastal settlement/infrastructure protection schemes (e.g. hard engineering structures) is often done via the application of numerical modelling approaches. These modelling approaches can vary from simple analytical expressions (e.g. the Bruun Rule ${ }^{7}$ ), to one-line models (e.g. GENESIS ${ }^{8,9}, \mathrm{UNIBEST}^{9}$ ), to semi-empirical models (e.g. SBEACH ${ }^{10}$ ), and to very sophisticated, three-dimensional coastal morphodynamic models (e.g. Delft $3 \mathrm{D}^{11}$, MIKE2 $1^{12}, \mathrm{XBeach}^{13}$ ). One of the key parameters used in many of these models (except in the case of fully process based models) is the depth of closure (DoC, $\left.h_{c}\right)^{6-9,14-18}$. The DoC, which increases with the time scale under consideration $^{19}$, is defined as the seaward depth at which sediment transport and consequent bed level change are insignificant. The time scale dependency of the $\mathrm{DoC}$ is illustrated by Cowell and Kinsela ${ }^{20}$ who developed a

\footnotetext{
${ }^{1}$ International Research Institute of Disaster Science, Tohoku University, 468-1 Aoba, Sendai, 980-8572, Japan. ${ }^{2}$ Department of Water Science and Engineering, IHE-Delft P.O. Box 30152610 DA, Delft, The Netherlands. ${ }^{3}$ Harbour, Coastal and Offshore Engineering, Deltares, PO Box 177, 2600, MH, Delft, The Netherlands. ${ }^{4}$ Water Engineering and Management, Faculty of Engineering Technology, University of Twente, PO Box 217, 7500, AE, Enschede, The Netherlands. *email: udo@irides.tohoku.ac.jp
} 
framework for investigating shoreface morphologic-response timescales based on Hallermeier ${ }^{21,22}$ and Stive and deVriend ${ }^{23}$ as follows:

- The upper shoreface, which is affected by wave breaking and surf zone processes;

- The active shoreface, which implicitly includes the upper shoreface, and is characterized as having statistically stationary geometry at the observation timescale; and

- The lower shoreface, which is affected by wave shoaling, where profile response is immeasurable or insignificant at the observation timescale.

The timescales of upper, active, and lower shoreface responses could be determined as less than years, years to decades, and decades to centuries, respectively. In this framework, the DoC formulation by Hallermeier ${ }^{21,22}$ would typically be located around the seaward limit of the upper shoreface. While many studies have focused on $\mathrm{DoC}^{21,22,24-30}$, the DoC is still often computed using Hallermeier's ${ }^{21,22}$ formulations or derivatives thereof, which were intended to capture the limit of profile variability at annual timescales.

Hallermeier ${ }^{21}$ used the Shields parameter to derive the following equation regarding $h_{c}$ :

$$
k h_{c} \sinh ^{2}\left(k h_{c}\right) \tanh ^{2}\left(k h_{c}\right)\left(1+\frac{\left(2 k h_{c}\right)}{\sinh \left(2 k h_{c}\right)}\right)=\frac{329 \rho H_{0}^{2}}{\left(\rho_{s}-\rho\right) L_{0}^{2}},
$$

where $k$ is the wave number; $H_{0}$ and $L_{0}$ are the deep water wave height and length, respectively; and $\rho$ and $\rho_{\mathrm{s}}$ are the densities of fluids $\left(1.03 \mathrm{~kg} \mathrm{~m}^{-3}\right.$, salt water) and sand particles $\left(2.65 \mathrm{~kg} \mathrm{~m}^{-3}\right)$, respectively. The value of $k h_{c}$ can be obtained numerically if deep water wave values are given; then $h_{c}$ can be solved using the dispersion relationship $^{31}$. Hallermeier ${ }^{21}$ found that $h_{c}$ obtained from Eq. (1) agreed well with laboratory measurements. Following a detailed analysis, Hallermeier ${ }^{21}$ proposed the well-known equation for $h_{c}$ as:

$$
h_{c}=a H_{e}+b\left(H_{e}^{2} / g T_{e}^{2}\right)
$$

where $H_{e}$ is the nearshore significant wave height that is exceeded for only 12 hours a year, $T_{e}$ is the associated wave period, and $g$ is the gravitational acceleration. Coefficients $a$ and $b$ are given by 2.28 and -68.5 , respectively (hereon, these coefficient values are referred to as "HM"). Birkemeier ${ }^{24}$ applied Eq. (2) to beach-nearshore profile data and wave data at a depth of $18 \mathrm{~m}$ from June 1981 to December 1982 also at the USACE Field Research Facility, Duck, North Carolina (USA) and determined the coefficients $a$ and $b$ to be 1.75 and -57.9 (hereon, these values are referred to as "BM1"). Birkemeier ${ }^{24}$ noted that a reasonable fit could also be obtained when using $H_{e}$ alone but by forcing the regression through the origin. In this latter approach, the values of coefficients determined for $a$ and $b$ are 1.57 and 0.0 (referred to as "BM2"). Nicholls et $a l^{25}$. also evaluated the applicability of Eq. (2) over periods up to four years using 12 years (July 1981 to July 1993) of beach profile data collected at Duck using a time-dependent form of Eq. (2):

$$
h_{c, t}=a H_{e, t}+b\left(H_{e, t}{ }^{2} / g T_{e, t}{ }^{2}\right)
$$

where $H_{e, t}$ is the significant wave height that is exceeded for only 12 hours in $t$ years and $T_{e, t}$ is the associated wave period (hereinafter, time-dependent $h_{c, t}, H_{e, t}$ and $T_{e, t}$ are expressed as $h_{c}, H_{e}$ and $T_{e}$ because we conducted only time-dependent analysis). Nicholls et al $l^{25}$. showed that the observed DoC was $69 \%$ of the estimated DoC when using Eq. (3) with Hallermeier's ${ }^{21,22}$ coefficients; however, they indicated that Hallermeier's ${ }^{21,22}$ approach provides a reasonable representation of $\mathrm{DoC}$ for periods up to four years. They also demonstrated that the DoC increases with observation time scale.

Most DoC studies have focused only on a single transect profile because repeated profile data are not generally available. An exception is the recent study reported by Patterson and Nielsen ${ }^{32}$, which used multiple-transect profile data from 1966 to 2012 and wave data measurements since 1986 at northern Gold Coast, Australia. Also, Hartman and Kennedy ${ }^{27}$ investigated DoC for a $2 \mathrm{~km}$ long beach region using the Joint Airborne Lidar Bathymetry Technical Center of Expertise (JALBTCX) dataset collected for sandy coastlines in Florida over the past decade. They used a bathymetry dataset containing 19 surveys from 2004-2012; however, their analysis was limited by wave data sourced from Wave Information Studies (WIS) wave hindcast models which did not include the effects of tide and storm surge. They concluded that the accuracy of DoC calculations could be further improved using wave hindcast models that contain storm surge water level variations as well as those with higher nearshore resolution ${ }^{27}$. Valiente et $\mathrm{l}^{29}$. compared the DoC observed using beach profile data at Perranporth, UK, to that estimated using Eq. (3) fed by the output of a $8-\mathrm{km}$ resolution regional wave forecast model based upon WAVEWATCH III from 2010-2016, and concluded that DoC was estimated with adequate accuracy by Eq. (3). Ideally the $\mathrm{DoC}$ at a given location would be estimated using repeated profile measurements over a long period of time (decade or more). However, such data is hardly available, and therefore, while the applicability of Eq. (3) appears to have been validated at a few sandy coasts, its validity in other parts of the world, and especially over longer time scales still remains unknown.

The DoC equations formulated by Hallermeier's ${ }^{21,22}$ approach are widely used; nevertheless, there are still two major unresolved issues associated with computing the DoC in this way: (i) the accuracy of the wave data required for reliable DoC computations, and (ii) the generic applicability of the coefficients used in DoC equations. Here we assess the applicability of Eq. (3) by comparing the DoCs measured at eight study locations around Japan (Table 1 and Fig. 1) with those computed using the equation with both observed and reanalysis wave data, to gain new insights on these knowledge gaps. First we evaluate the reanalysis wave data (i.e., Coastal Wave Model, $\mathrm{CWM}^{33}$; WAVEWATCH III ${ }^{34}$; and $\mathrm{ERA}^{35}$ ) by comparing them with the observed wave data (i.e., the 


\begin{tabular}{|c|c|c|c|c|c|c|c|c|}
\hline Location No. & 1 & 2 & 3 & 4 & 5 & 6 & 7 & 8 \\
\hline Location name & Sendai & Soma & Onahama & Kashima & Sakata & Niigata & Tottori & Ainoshima \\
\hline Longitude [deg] & 141.2190 & 140.9852 & 140.7731 & 140.6290 & 139.8047 & 138.9640 & 134.2054 & 130.8920 \\
\hline Latitude [deg] & 38.3971 & 37.7856 & 36.8219 & 36.0501 & 38.9102 & 37.8896 & 35.5417 & 34.1363 \\
\hline Profile data period [year] & $\begin{array}{l}1973-1984(11 \\
\text { years })\end{array}$ & $\begin{array}{l}1977-1991(14 \\
\text { years })\end{array}$ & $\begin{array}{l}1979-1988(9 \\
\text { years })\end{array}$ & $\begin{array}{l}1983-1992(9 \\
\text { years })\end{array}$ & $\begin{array}{l}1975-1990(15 \\
\text { years })\end{array}$ & $\begin{array}{l}1982-1989(7 \\
\text { years })\end{array}$ & $1974-1985$ ( 11 years) & $\begin{array}{l}1980-1987(7 \\
\text { years })\end{array}$ \\
\hline $\begin{array}{l}\text { Profile measurement } \\
\text { timing }\end{array}$ & 2 & 3 & 2 & 10 & 15 & 3 & 10 & 6 \\
\hline $\begin{array}{l}\text { Number of profile } \\
\text { transects }\end{array}$ & 5 & 2 & 1 & Bathymetry & 2 & 4 & Bathymetry (140) & 1 \\
\hline Observed DoC [m] & 9 & 10 & 9 & 8 & $>15$ & 12 & 14 & 7 \\
\hline NOWPHAS station code & 205 & 214 & 206 & 207 & 102 & 110 & 304 & 406 \\
\hline $\begin{array}{l}\text { NOWPHAS available data } \\
\text { period [year] }\end{array}$ & 1979-present & 1982-present & 1980-present & 1972-present & 1970-present & 1982-present & 1979-present & 1975-present \\
\hline $\mathrm{He} 12[\mathrm{~m}]$ & 4.99 & 5.01 & 5.85 & 5.97 & 7.56 & 5.36 & 5.79 & 4.20 \\
\hline $\mathrm{Te} 12[\mathrm{~s}]$ & 13.3 & 11.2 & 13.8 & 12.3 & 10.4 & 9.2 & 9.4 & 10.3 \\
\hline $\begin{array}{l}\text { Water depth of } \\
\text { NOWPHAS measurement } \\
{[\mathrm{m}]}\end{array}$ & 20.0 & 16.0 & 20.0 & 24.5 & 20.4 & 22.7 & 30.0 & 20.7 \\
\hline $\begin{array}{l}\text { Distance between Study } \\
\text { sites and NOWPHAS [km] }\end{array}$ & 21 & 9 & 17 & 20 & 11 & 11 & 7 & 17 \\
\hline
\end{tabular}

Table 1. Details of beach profile and wave observation data for the eight locations shown in Fig. 1. See also Fig. $\mathrm{S} 1$ for an example of profile data.

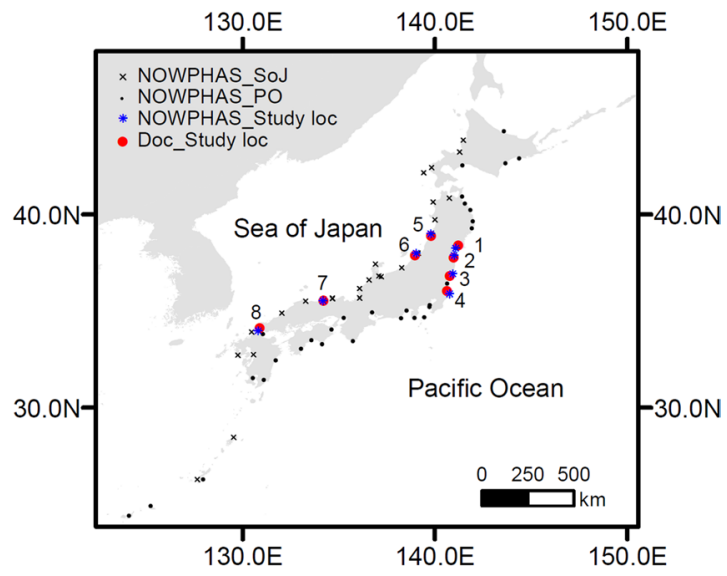

Figure 1. Locations of wave observation (NOWPHAS) stations used for the wave analysis, and the eight beach profile measurement sites together with the closest NOWPHAS stations used in the DoC analysis. Details on study sites are given in Table 1 .

Nationwide Ocean Wave information network for Ports and HArbourS, NOWPHAS ${ }^{36}$ ) and then use both the reanalysis and observed wave data to estimate DoCs. Finally the applicability of the DoC equation is evaluated by comparing computed DoCs with Uda's ${ }^{30}$ and others' unique years-to-decadal measured DoCs around the Japanese coast (see Fig. S1).

\section{Results and Discussion}

Evaluation of reanalysis wave data. Spatial distributions of reanalysis wave heights $\left(H_{\text {mean }}\right.$ and $\left.H_{e}\right)$ and periods $\left(T_{\text {mean }}\right.$ and $\left.T_{e}\right)$ for reanalysis wave datasets $\left(\mathrm{CWM}^{33}\right.$, WAVEWATCH III ${ }^{34}$, and ERA $\left.5^{35}\right)$ around Japan are shown in Figs. S2 and S3, respectively. The CWM dataset is computed only around Japan with higher resolution of 5 to $10 \mathrm{~km}$, and WAVEWATCH III and ERA 5 are often-used and computed globally with relatively lower resolution (Table S1). It is apparent that mean and 12 hour exceedance wave distributions are larger in the Pacific Ocean and smaller in the Japan Sea. The wave height distributions show approximately similar distributions for all models; however, the ERA5 derived wave periods are smaller compared to those of CWM and WAVEWATCH III.

Reanalysis values during the period of 2005 to 2009 are also compared with NOWPHAS observation data at 62 measurement points along the coast (see Fig. 1) as shown in Figs. 2 and 3. The period bounded by 2005 and 2009 was selected for this analysis due to two reasons: (i) before the mid 2000s and after the 2011 Tohoku Tsunami, the number of the wave stations and the data acquisition rate of NOWPHAS network was sub-optimal, and (ii) the WAVEWATCH III reanalysis extends only up to 2009. Overall, CWM gives a good agreement with 

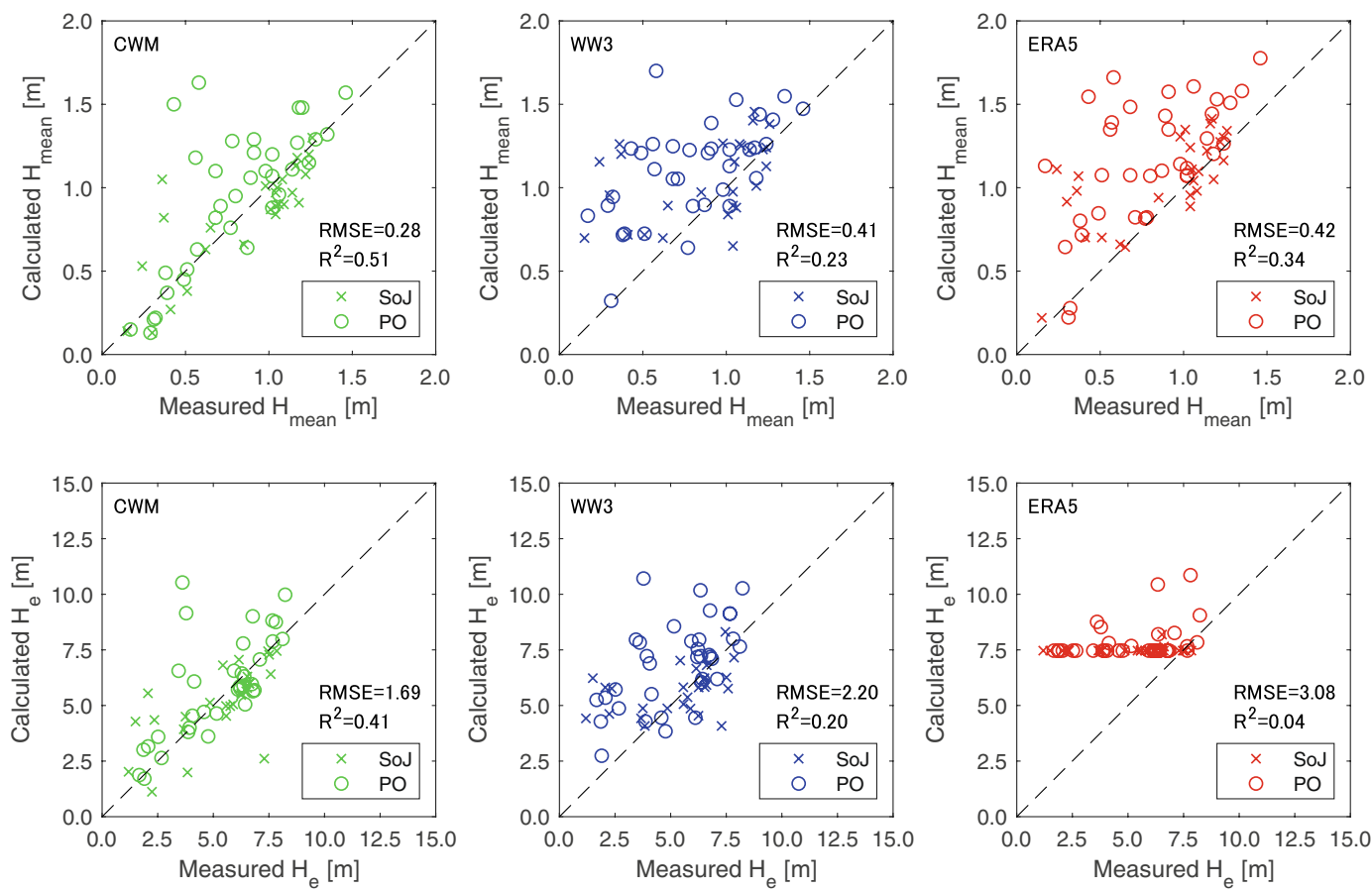

Figure 2. Comparisons between observed Nationwide Ocean Wave information network for Ports and HArbourS (NOWPHAS) and reanalysis wave height data (CWM, WAVEWATCH III, and ERA5) in the period for 2005-2009. SoJ and PO indicate wave data obtained in the Sea of Japan and the Pacific Ocean sides, respectively.
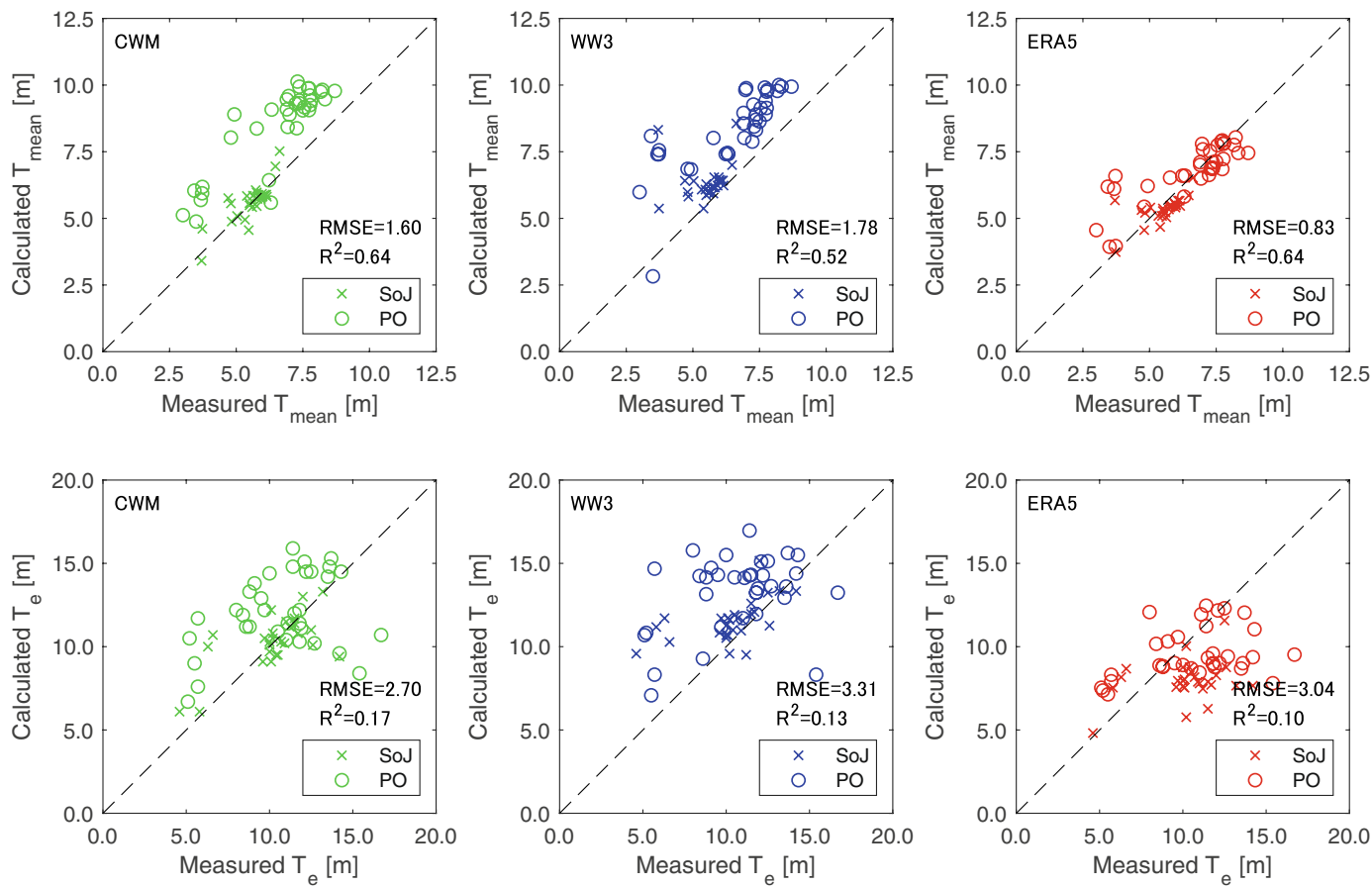

Figure 3. Same as Fig. 2 but for wave period data.

the NOWPHAS data. ERA5 shows a better agreement than WAVEWATCH III for $H_{\text {mean }}$ and $T_{\text {mean }}$ obtained from NOWPHAS data; however, $H_{e}$ and $T_{e}$ obtained from both global reanalysis products do not agree well with that computed from NOWPHAS data. The better agreement of CWM appears to be linked to the spatial resolution of the reanalysis data because most of the model/data disparities occur in small wave shelter zones such as bays. Such locations are therefore not included in the study sites in the DoC analysis. 

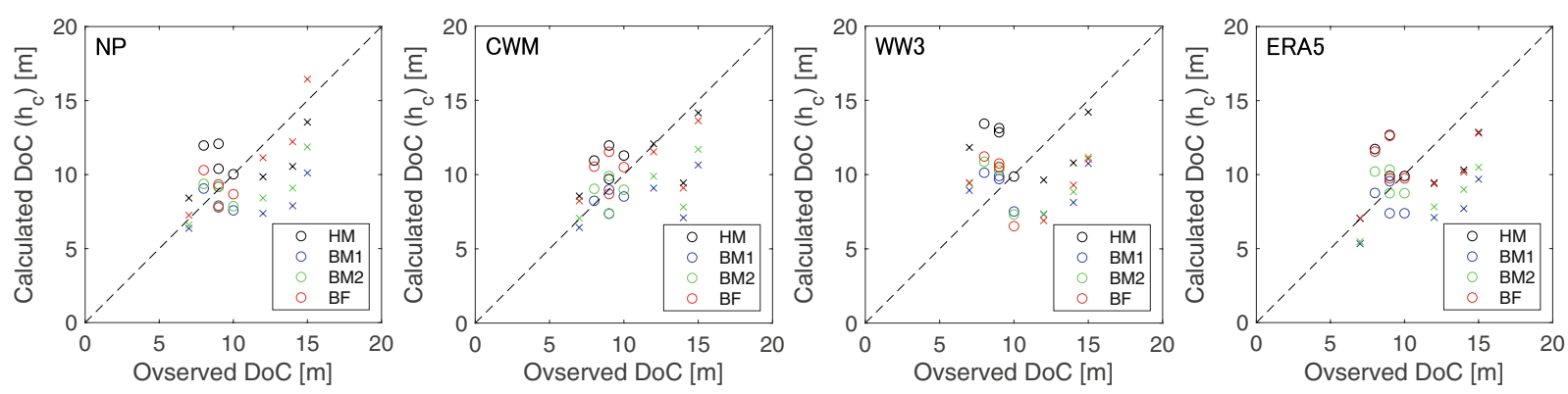

Figure 4. Comparisons of observed DoCs and DoCs derived from Eq. (3) with $H_{e}$ of observed (NOWPHAS) and reanalysis wave height data (CWM, WAVEWATCH III, and ERA5) at the eight study locations. Black, blue, green, and red symbols indicate plots for $\mathrm{HM}, \mathrm{BM} 1, \mathrm{BM} 2$, and BF models, and circle and cross symbols indicate plots for the Sea of Japan and the Pacific Ocean side locations, respectively. The observed DoC values are also shown in Table 1.

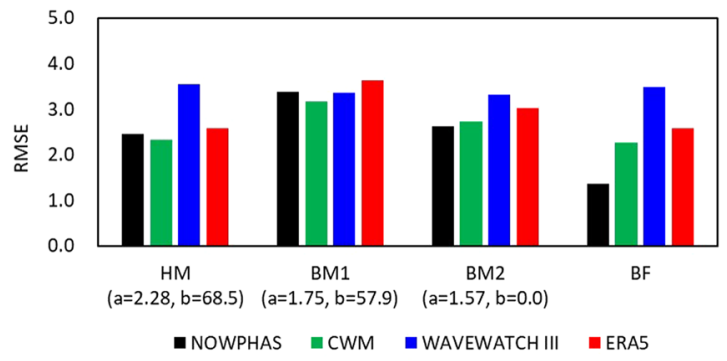

Figure 5. Root mean square errors (RMSE) of DoCs derived from Eq. (3). Note that the data period of CWM is different to that of the period of profile measurement due to data availability. See also Fig. 4.

DoC evaluation. The DoC $\left(h_{c}\right)$ were estimated using the 12-hour exceedance wave data during the same period as the profile measurements for determining the observed $\mathrm{DoC}$ (see Table 1 and Fig. S1). Similar to previous studies ${ }^{25,27,29}$, DoC estimates obtained using Hallermeier ${ }^{21,22}$ appear to be acceptable (Fig. 4). It is noteworthy that all three DoC models (HM, BM1, and BM2) tend to overestimate DoC along the Pacific Ocean side and underestimate DoC along the Sea of Japan side. Our results also show that the DoC RMSEs, except for WAVEWATCH III, are smaller for HM compared to BM1 and BM2 (Fig. 5). Among the DoCs calculated using wave reanalysis data, those obtained from high resolution CWM data consistently outperforms the coarser resolution ERA5 and WAVEWATCH III data, implying that wave model resolution does matter for DoC calculations. Furthermore, the coefficients $a$ and $b$ of the best fit model for the DoCs calculated using observed wave data are 1.14 and 144.8, respectively, while those for the DoCs calculated using reanalysis wave data display wide ranges of 1.20-2.32 and -77.7-85.1, respectively (hereon, the best-fit coefficients are referred to as "BF") as shown in Table S2, indicating that coefficients proposed by previous studies are location dependent as Birkemeier ${ }^{24}$ also mentioned. Among the BF DoCs calculated using wave reanalysis data, the DoC calculated using CWM has the smallest RMSE, while the WAVEWATCH III DoC has the largest RMSE, reinforcing the superior performance of the high resolution CWM data compared to the lower resolution global reanalysis products in terms of DoC calculations. Note that the CWM data period 2005-2009 shown in Figs. S2 and S3 was used for the estimation since CWM results were not available for the profile measurement period.

We found that the coefficients $a$ and $b$ of HM, BM1, and BM2 and the four BFs for the wave data display a positive linear relationship $\left(R^{2}=0.87, p<0.005\right)$, although the number of their data points is limited to seven (see Table S2). We also found that the Hallermeier's coefficients for 19 datasets classified according to parameters including bed slope, sediment size, and wave geometry ${ }^{21}$ also display a positive linear relationship, which suggests that DoC may be better estimated by determining suitable coefficients using such aggregated parameters.

\section{Conclusions}

In this study we combined DoC and continuous wave observations from multiple sandy beaches in Japan with wave reanalysis data to evaluate the relative merits of commonly used empirical equations for determining DoCs. Results indicated that the accuracy of DoCs determined using reanalysis wave data is limited by the spatial resolution of the reanalysis. Based on our results, we suggest that DoC equation coefficients proposed in previous and present studies may in fact be location dependent, and hence, not generically applicable to coastal regions globally, although it should be noted that the low number of study sites (8) in this study does limit our ability to draw more definitive conclusions. The outcomes of this study point towards the need for a worldwide meta-analysis that compares observed and derived DoC in order to derive a globally applicable formulation for DoC computations. 


\begin{abstract}
Methods
Wave analysis. Two-hourly time-series of significant wave height and period data from the Nationwide Ocean Wave information network for Ports and HArbourS (NOWPHAS) ${ }^{36}$, provided by the Ports and Harbours Bureau, Ministry of Land, Infrastructure, Transport, and Tourism (MLIT), were used in this study. Five NOWPHAS stations were in operation in 1970 and this increased to more than sixty stations by the mid 2000s (Fig. 1). In the latter half of the 2000 decade, the temporal data acquisition rate was more than $80 \%$ at most locations. However, following the 2011 Tohoku Tsunami, data was not recorded for several years in tsunami affected areas. NOWPHAS wave data is collected by ultrasonic wave gauges, step-type wave gauges, or Doppler-type directional wave meters. Available wave data period, water depth of wave measurements, and wave measurement instrument type at the study sites are shown in Table 1 . We note that the available wave data period does not cover the entire profile measurement period for several study sites.

Reanalysis wave datasets, i.e. significant height and mean wave period, used in this study included the Coastal Wave Model (CWM) data from the Japan Meteorological Agency (JMA) ${ }^{33}$, WAVEWATCH III data from the National Oceanic and Atmospheric Administration (NOAA) ${ }^{34}$, and ERA5 data from the European Centre for Medium-Range Weather Forecasts (ECMWF) ${ }^{35}$ (Table S1). The CWM dataset was generated using the third generation wave model MRI-III (since March 2002) and wind grid point values forecast by the JMA operational weather model, upgraded in May 2007 33,37 . The CWM has hindcast real-time wave conditions around Japan using reanalysis wind data twelve hourly from March 2002 to May 2007 and six hourly since May 2007. An 84 hour (three hourly) wave forecast is also provided. The spatial resolution of the model also increased from 0.1 to $0.05^{\circ}$ in May 2007 and is high as compared to other reanalysis data. WAVEWATCH III provides three hourly data from 1979-2009 at a spatial resolution of $0.5^{\circ}$ and ERA5 provides hourly data at $0.5^{\circ}$ from 1979 to the present. Mean and 12-hour exceedance significant wave heights and periods from 2005-2009 (i.e., $H_{\text {mean }}, H_{e}, T_{\text {mean }}$, and $T_{e}$, respectively) were calculated for the observed and reanalysis wave data at 62 measurement points with a temporal acquisition rate exceeding $80 \%$. The reanalysis wave data were compared with observations.
\end{abstract}

DoC analysis. More than 50 Japanese beaches for which DoCs were presented in Uda ${ }^{30}$ were initially considered as potential study sites for this study. The profiles had been generally measured by level surveys in the intertidal area and by acoustic bathymetric survey in the subtidal area ${ }^{30}$. To improve the accuracy of our analysis, this data set was first narrowed down by considering only the sites for which (i) beach profile data for at least a five-year period, and (ii) wave data within $20 \mathrm{~km}$ of profile measurement locations were available. Concerning the accuracy of DoC observations, Valiente et $a^{29}$. indicated five criteria of which the most used criteria is the minimum depth of the uncertainty limit for detecting significant morphologic change (e.g., $\Delta d<0.03 \mathrm{~m}^{24}$ and $0.06 \mathrm{~m}^{25}$ for the data obtained by Coastal Research Amphibious Buggy (CRAB) and $\Delta d<0.14 \mathrm{~m}^{29}$ for the data obtained by single-beam echo-sounder). $\mathrm{Uda}^{38}$ demonstrated that the accuracy of annual profile data measured by acoustic surveys from 1976-1987 along the coastline of the Niigata Prefecture was $0.28 \mathrm{~m}$; and therefore, the observed DoCs used herein can be considered to have an accuracy of $0.28 \mathrm{~m}$.

Based on wave data and profile data availability, eight study locations were ultimately chosen for this study (see Table 1 and Fig. 1). At the selected sites, DoC was calculated using Eq. (3) with both observed and reanalysis wave data, and then the derived DoC was compared with observed DoC. The best-fit model of Eq. (3) for each reanalysis dataset was obtained by determining the coefficients $a$ and $b$ using minimum RMSE (see Table S2).

\title{
Data availability
}

Data used to derive the tables and figures shown in this manuscript is available in xlsx format. Original wave reanalysis data is available from CWM, WAVEWATCH III, and ERA5.

Received: 14 May 2019; Accepted: 3 February 2020;

Published online: 19 February 2020

\section{References}

1. Small, C. \& Nicholls, R. J. A global analysis of human settlement in coastal zones. Journal of Coastal Research. 33, 584-599 (2003).

2. Hallegatte, S., Green, C., Nicholls, R. J. \& Corfee-Morlot, J. Future flood losses in major coastal cities. Nature Climate Change. 3, 802-806 (2013).

3. Hinkel, J. et al. A global analysis of coastal erosion of beaches due to sea-level rise: an application of DIVA. Global and Planetary Change. 111, 150-158 (2013).

4. McGranahan, G., Balk, D. \& Anderson, B. The rising tide: assessing the risks of climate change and human settlements in low elevation coastal zones. Environment and Urbanization. 19, 17-37 (2007).

5. Nicholls, R. J. et al. Coastal systems and low-lying areas. In Climate Change 2007: Impacts, Adaptation and Vulnerability, Contribution of Working Group II to the Fourth Assessment Report of the Intergovernmental Panel on Climate Change. Cambridge University Press, Cambridge, UK. (2007).

6. Ranasinghe, R. Assessing Climate change impacts on coasts: a review. Earth Science Reviews 160, 320-332 (2016).

7. Bruun, P. Sea-level rise as a cause of shore erosion. J. Waterways and Harbors Div. 88, 117-130 (1962).

8. Hanson, H. GENESIS - A generalized shoreline change numerical model. J. Coast. Res. 5, 1-27 (1989).

9. Szmytkiewicz, M. et al. Coastline changes nearby harbour structures: comparative analysis of one-line models versus field data. Coast. Eng. 40, 119-139 (2000).

10. Larson, M. \& Kraus, N. C. SBEACH: numerical model for simulating storm-induced beach change. Report 1. Empirical foundation and model development, Technical Report CERC-89-9. Coastal Engineering Research Center, U.S. Army Engineer Waterways Experiment Station, Vicksburg, MS, p. 267 (1989).

11. Lesser, G., Roelvink, J. A., Van Kester, J. A. T. M. \& Stelling, G. S. Development and validation of a three-dimensional morphological model. Coast. Eng. 51, 883-915 (2004).

12. DHI. MIKE 21/3 Flow Model FM Hydrodynamic and Transport Module Scientific Documentation. DHI Group, Horshølm (2005).

13. Roelvink, D. et al. Modelling storm impacts on beaches, dunes and barrier islands. Coastal Engineering. 56, 1133-1152 (2009). 
14. Stive, M. J. F., De Vriend, H. J., Nicholls, R. J. \& Capobianco, M. Shore nourishment and the active zone: a time scale dependent view. Proc. 23rd International Conference on Coastal Engineering. 2464-2473 (1992).

15. Masselink, G. \& Hughes, M. G. An introduction to coastal processes and geomorphology. Routledge (2014).

16. Udo, K. \& Takeda, Y. Projections of future beach loss in Japan due to sea-level rise and uncertainties in projected beach loss. Coastal Engineering Journal. 59, 1740006 (2017).

17. Ritphring, S., Somphong, C., Udo, K. \& Kazama, S. Projections of future beach loss due to sea level rise for sandy beaches along Thailand's coastlines. Journal of Coastal Research. SI 85, 541-545 (2018).

18. Ranasinghe, R., Callaghan, D. \& Stive, M. J. F. Estimating coastal recession due to sea level rise: beyond the Bruun Rule. Climatic Change. 110, 561-574 (2012).

19. Cowell, P. J. et al. The shoreface. In: Handbook of beach and shoreface morphodynamics (ed. Short, A. D.). Wiley, New York, 39-71 (1999).

20. Cowell, P. J., and M. A. Kinsela. Shoreface Controls on Barrier Evolution and Shoreline Change. In Barrier Dynamics and Response to Changing Climate (eds. Moore, L. J. and Murray, A. B.). Springer International, 243-275 (2018).

21. Hallermeier, R. J. Uses for a calculated limit depth to beach erosion. Proc. 16th International Conference on Coastal Engineering. 1493-1512 (1978).

22. Hallermeier, R. J. A profile zonation for seasonal sand beaches from wave climate. Coastal Eng. 4, 253-277 (1981).

23. Stive, M. J. F. \& de Vriend, H. J. Modeling shoreface profile evolution. Marine Geology 126, 235-248 (1995).

24. Birkemeier, W. A. Field data on seaward limit of profile change. Journal of Waterway, Port, Coastal, and Ocean Engineering. 111, 598-602 (1985).

25. Nicholls, R. J., Birkemeier, W. A. \& Lee, G. H. Evaluation of depth of closure using data from Duck, NC, USA. Marine Geology 148, 179-201 (1998).

26. Robertson, W., Zhang, K., Finkl, C. W. \& Whitman, D. Hydrodynamic and geologic influence of event-dependent depth of closure along the South Florida Atlantic Coast. Marine Geology. 252, 156-165 (2008).

27. Hartman, M. \& Kennedy, A. B. Depth of closure over large regions using airborne bathymetric lidar. Marine Geology. 379, 52-63 (2016).

28. Ortiz, A. C. \& Ashton, A. D. Exploring shoreface dynamics and a mechanistic explanation for a morphodynamic depth of closure. Journal of Geophysical Research: Earth Surface. 121, 442-464 (2016).

29. Valiente, N. G., Masselink, G., Scott, T., Conley, D. \& McCarroll, J. Role of waves and tides on depth of closure and potential for headland bypassing. Marine Geology. 407, 60-75 (2019).

30. Uda, T. Japan's beach erosion. Sankaido Publishing Co., Ltd. (1996). (in Japanese)

31. Dean, R. G. \& Dalrymple, R. A. Coastal Processes with Engineering Applications. Cambridge University Press (2001).

32. Patterson, D. C. \& Nielsen, P. Depth, bed slope and wave climate dependence of long term average sand transport across the lower shoreface. Coastal Engineering 117, 113-125 (2016).

33. Tauchi, T., Kohno, N. \& Kimura, M. The improvement of JMA operational wave models, https://www.wmo.int/pages/prog/amp/ mmop/documents/JCOMM-TR/J-TR-44/WWW/Papers/Full_WaveW2007Tauchi.pdf (2007).

34. Chawla, A., Spindler, D. M. \& Tolman, H. L. Validation of a thirty year wave hindcast using the Climate Forecast System Reanalysis winds. Ocean Modelling. 70, 189-206 (2013).

35. Hersbach, H. et al. Operational global reanalysis: progress, future directions and synergies with NWP. ECMWF ERA Report Series 27 (2018).

36. Kawai, H. et al. Characteristics of the 2011 Tohoku Tsunami waveform acquired around Japan by NOWPHAS equipment. Coastal Engineering Journal 55, 1350008 (2013).

37. Ueno, K. \& Kohno, N. The development of the third generation wave model MRI-III for operational use. In Proc. of 8th Int. Workshop on Wave Hindcasting and Forecasting, G2, 1-7 (2004).

38. Uda, T. \& Togawa, K. A study on accuivey and analysis method of wielding data. Proceedings of Civil Engineering in the Ocean 11, 265-270 (1995). (in Japanese).

\section{Acknowledgements}

The authors would like to thank to Dr. Takaaki Uda for helpful information on the depth of closure at Japanese beaches. This research was supported by JSPS KAKENHI Grant Number 15KK0223, Social Implementation Program on Climate Change Adaptation Technology (SI-CAT) of MEXT. RR is supported by the AXA Research Fund and the Deltares Strategic Research Programme "Coastal and Offshore Engineering".

\section{Author contributions}

K.U. was responsible for organizing the research and writing the manuscript. R.R. contributed to the design of the analysis and writing the manuscript. Y.T. was responsible for the data analysis. All authors discussed the results and contributed to preparing the final manuscript.

\section{Competing interests}

The authors declare no competing interests.

\section{Additional information}

Supplementary information is available for this paper at https://doi.org/10.1038/s41598-020-59718-5.

Correspondence and requests for materials should be addressed to K.U.

Reprints and permissions information is available at www.nature.com/reprints.

Publisher's note Springer Nature remains neutral with regard to jurisdictional claims in published maps and institutional affiliations. 
(c) (i) Open Access This article is licensed under a Creative Commons Attribution 4.0 International License, which permits use, sharing, adaptation, distribution and reproduction in any medium or format, as long as you give appropriate credit to the original author(s) and the source, provide a link to the Creative Commons license, and indicate if changes were made. The images or other third party material in this article are included in the article's Creative Commons license, unless indicated otherwise in a credit line to the material. If material is not included in the article's Creative Commons license and your intended use is not permitted by statutory regulation or exceeds the permitted use, you will need to obtain permission directly from the copyright holder. To view a copy of this license, visit http://creativecommons.org/licenses/by/4.0/.

(C) The Author(s) 2020 